\title{
Sistem Kontrol Peralatan Listrik Jarak Jauh Berbasis Arduino
}

\author{
Nauval Pramana Putra ${ }^{1}$, Irma Husnaini ${ }^{2}$ \\ 1,2Universitas Negeri Padang \\ Jl. Prof Dr. Hamka Air Tawar, Padang, Indonesia \\ nauvalpramanap@gmail.com ${ }^{1}$,irma hnni@ft.unp.ac.id ${ }^{2}$
}

\begin{abstract}
The need for electrical energy is vital because electrical equipment generally uses electricity as the main energy. Electricity is energy that comes from petroleum which must be saved in its use. To save electricity usage, it is necessary to use electricity as efficiently as possible by not allowing this energy to be wasted. This paper aims to design an application for controlling electrical equipment remotely using the internet network. This tool uses Esp8266 as a link with the internet network, and uses applications on Android as a controlling media. When esp8266 is connected to the internet network and the on / off button on the android application is pressed, the ac and fan lights will turn on or off according to the button pressed. The results of testing this remote electrical appliance controller are that the tool can work properly turning on or off the lights and fans when connected to the internet without distance restrictions.
\end{abstract}

Keywords: Android, Esp8266, AC Lamp, Fan

Abstrak-Kebutuhan akan energi listrik sangat vital karena peralatan listrik umumnya memakai energi listrik sebagai energi utama. Listrik adalah energi yang berasal dari minyak bumi yang harus dihemat penggunaannya. Untuk menghemat penggunaan listrik, maka harus memanfaatkan listrik se-efisian mungkin dengan tidak membiarkan energi ini terbuang percuma. Tulisan ini bertujuan merancang sebuah aplikasi pengontrolan peralatan listrik jarak jauh menggunakan jaringan internet. Alat ini menggunakan Esp8266 sebagai penghubung dengan jaringan internet, dan menggunakan aplikasi pada android sebagai media pengontrol. Saat esp8266 terhubung ke jaringan internet dan tombol on/off pada aplikasi android ditekan maka lampu Ac dan kipas angin akan hidup atau mati sesuai tombol yang ditekan. Hasil pengujian alat pengontrol peralatan listrik jarak jauh ini adalah alat dapat bekerja dengan baik menghidupkan atau mematikan lampu dan kipas angin saat terhubung dengan internet tanpa batasan jarak. Aplikasi melalui Esp8266 berbasis arduino dapat bekerja sesuai dengan yang direncanakan yaitu lampu dan kipas AC dapat hidup pada saat tambol on ditekan dan mati dengan tombol off ditekan dengan kecepatan internet dalam keadaan stabil.

Kata kunci : Android ,Esp8266, Lampu AC, Kipas angin

\section{Pendahuluan}

Kebutuhan akan energi listrik sangat vital karena peralatan listrik umumnya memakai energi listrik sebagai energi utama[1]. Listrik adalah energi yang berasal dari minyak bumi yang harus dihemat penggunaannya. Untuk menghemat penggunaan listrik, maka harus memanfaatkan listrik se-efisian mungkin[2]. Saat lupa mematikan peralatan listrik yang menyebabkan penggunaan listrik yang tidak efisien. Berdasarkan masalah tersebut penulis ingin membuat pengontrolan peralatan listrik dari jarak jauh dengan menggunakan jaringan internet berbasis arduino. Sistem ini menggunakan android dalam pengontrolan ON/Off nya peralatan listrik sehingga memudahkan pengguna dalam menghidupkan atau mematikan peralatan listrik pada rumah sesuai kebutuhan[3].

Pengendali jarak jauh adalah sebuah alat elektronik yang digunakan untuk mengoperasikan sebuah perangkat dari jarak jauh. Dan komponen pendukung lainnya yaitu Android merupakan salah satu sistem operasi berbasis mobile yang digunakan sebagai alat pengontrol peralatan listrik. Pengontrolan jarak jauh memiliki kelebihan yaitu dapat digunakan tanpa batasan jarak, dan untuk kekurangan dari pengontrolan jarak jauh yaitu dalam masalah ada atau tidaknya jaringan internet.

Android

Android adalah sistem operasi yang dirancang oleh Google dengan basis kernel Linux untuk mendukung kinerja perangkat elektronik layar sentuh, seperti tablet atau smartphone[4].

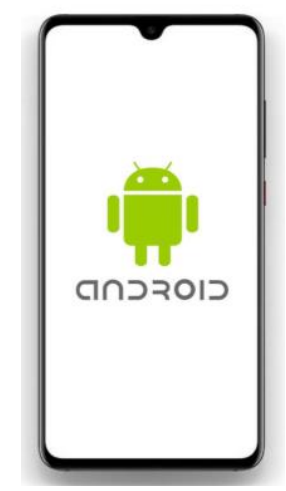

Gambar 1. Sistem Operasi Android Pada Smartphone 


\section{Arduino Uno}

Arduino Uno adalah papan sirkuit berbasis mikrokontroler ATmega328. IC (integrated circuit) ini memiliki 14 input/output digital ( 6 output untuk PWM), 6 analog input, resonator kristal keramik $16 \mathrm{MHz}$, Koneksi USB, soket adaptor, pin header ICSP, dan tombol reset. Untuk mensupport mikrokontroler terhubung ke komputer dapat dihubungkan melalui kabel USB. Berikut IC ATMega 328 pada gambar 2[5].

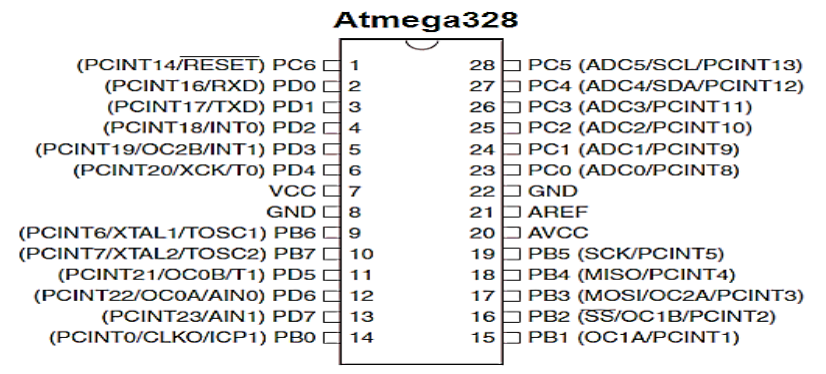

\section{Modul ESP8266}

Gambar 2. IC ATMega328

Modul ESP8266 merupakan sebuah modul internet sebagai perangkat tambahan pada mikrokontroler yang dapat terhubung langsung dengan WiFi dan membuat koneksi TCP/IP. Modul ini membutuhkan daya sekitar 3.3V dengan memiliki tiga mode WiFi yaitu Station, Access Point dan Both[6].

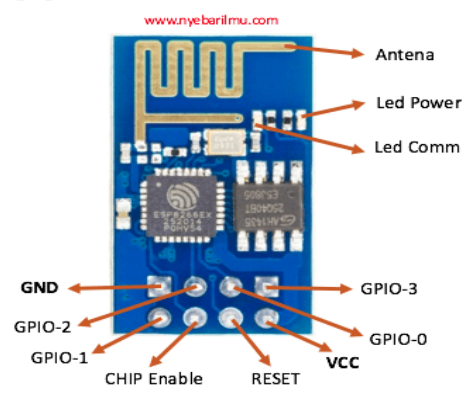

Gambar 3. Module ESP8266

\section{Driver Relay}

Relay adalah Saklar (Switch) yang dioperasikan dengan tegangan listrik dan merupakan komponen Electromechanical (Elektromekanikal) yang terdiri dari 2 bagian utama yakni Elektromagnet (Coil) dan Mekanikal (seperangkat Kontak Saklar/Switch). Relay terhubung ( menutup ) pada saat diberi sumber tegangan dan relay akan terputus (membuka) jika tidak diberi tegangan.

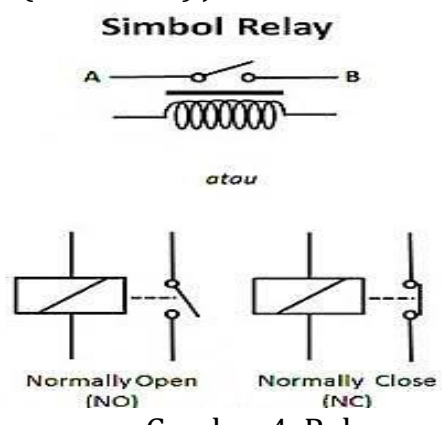

Gambar 4. Relay

\section{Bahasa Pemograman Android}

App Inventor memungkinkan pengguna baru untuk memprogram komputer untuk menciptakan aplikasi perangkat lunak bagi sistem operasi Android. App Inventor menggunakan antarmuka grafis, serupa dengan antarmuka pengguna pada Scratch dan StarLogo TNG, yang memungkinkan pengguna untuk men-dragand-drop objek visual untuk menciptakan aplikasi yang bisa dijalankan pada perangkat Android[7]

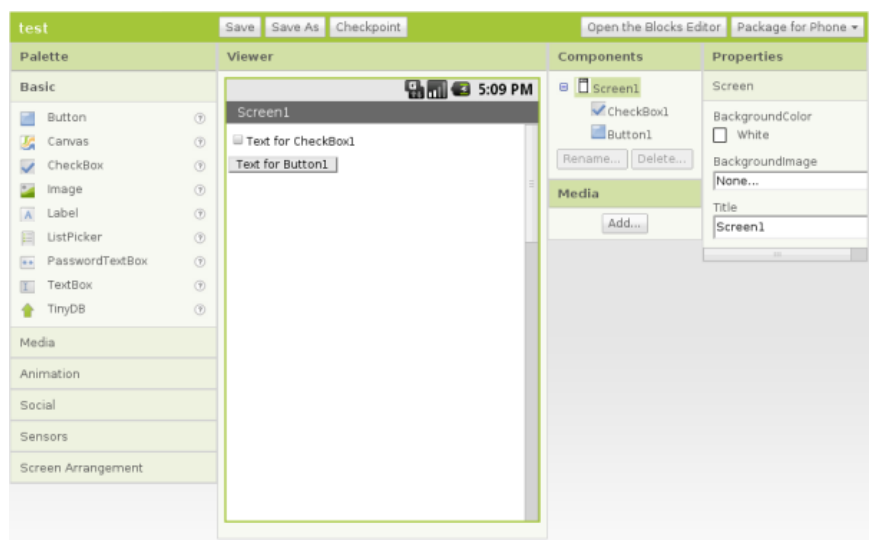

Gambar 5. Tampilan Awal MIT App Inventor

\section{Metode}

\section{Blok Diagram}

Blok diagram pada sistem kontrol peralatan listrik jarak jauh dapat dilihat pada gambar 6.

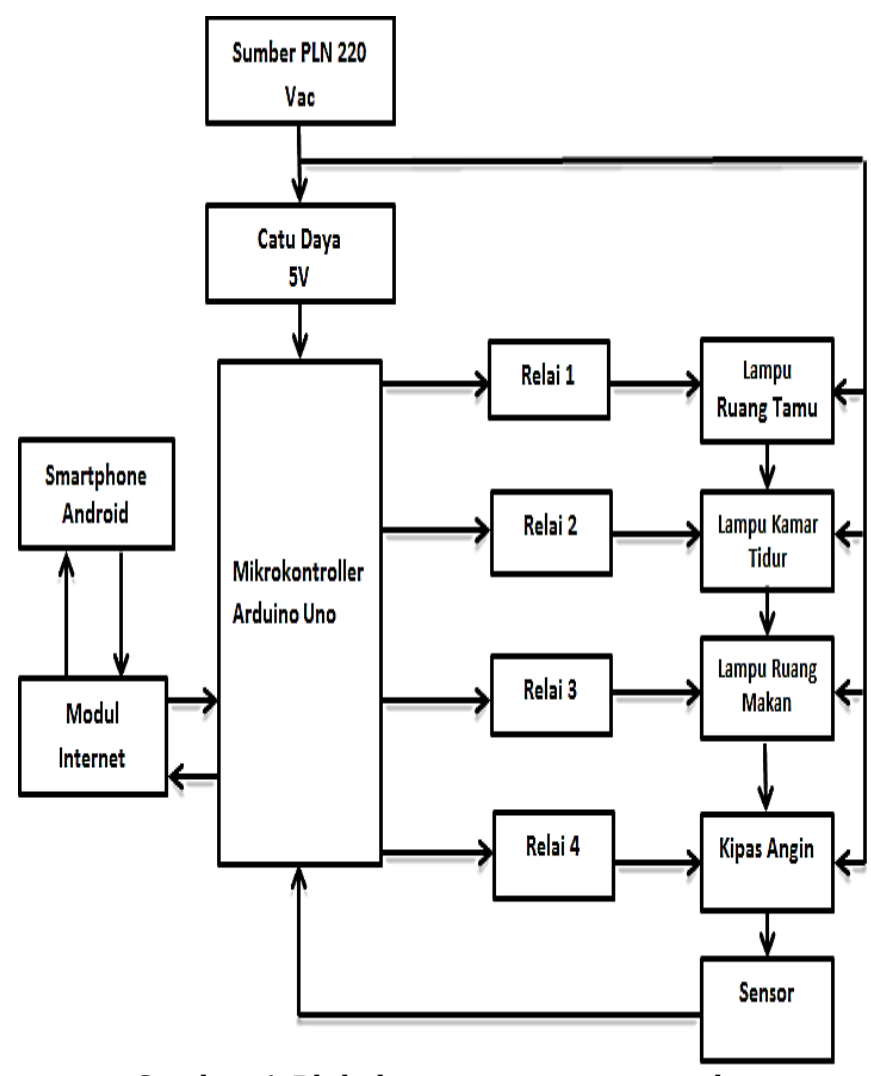

Gambar 6. Blok diagram perancangan alat 
Listrik dapat membuka aplikasi pada android, dan menghubungkan hotspot pada android untuk menghubungkan modul dengan internet. Jika sudah terhubung dapat menekan tombol ON atau OFF pada aplikasi android.

Perancangan alat dilakukan dengan untuk aplikasi pengontrolan peralatan listrik yang dapat difungsikan dari jarak jauh serta mempermudah pengguna untuk menghidup atau mematikan peralatan listrik dengan menggunakan androi. Alat ini bekerja dengan suplai tegangan $5 \mathrm{Vdc}$ yang digunakan untuk mensuplai arduino, driver relai, dan tegangan 3,3 Vdc untuk mensuplai modul internet. Prinsip kerja alat adalah sebagai berikut: Pada saat power suplay dihidupkan, arduino dan modul dalam keadaan ON. Untuk menghidupkan peralatan.

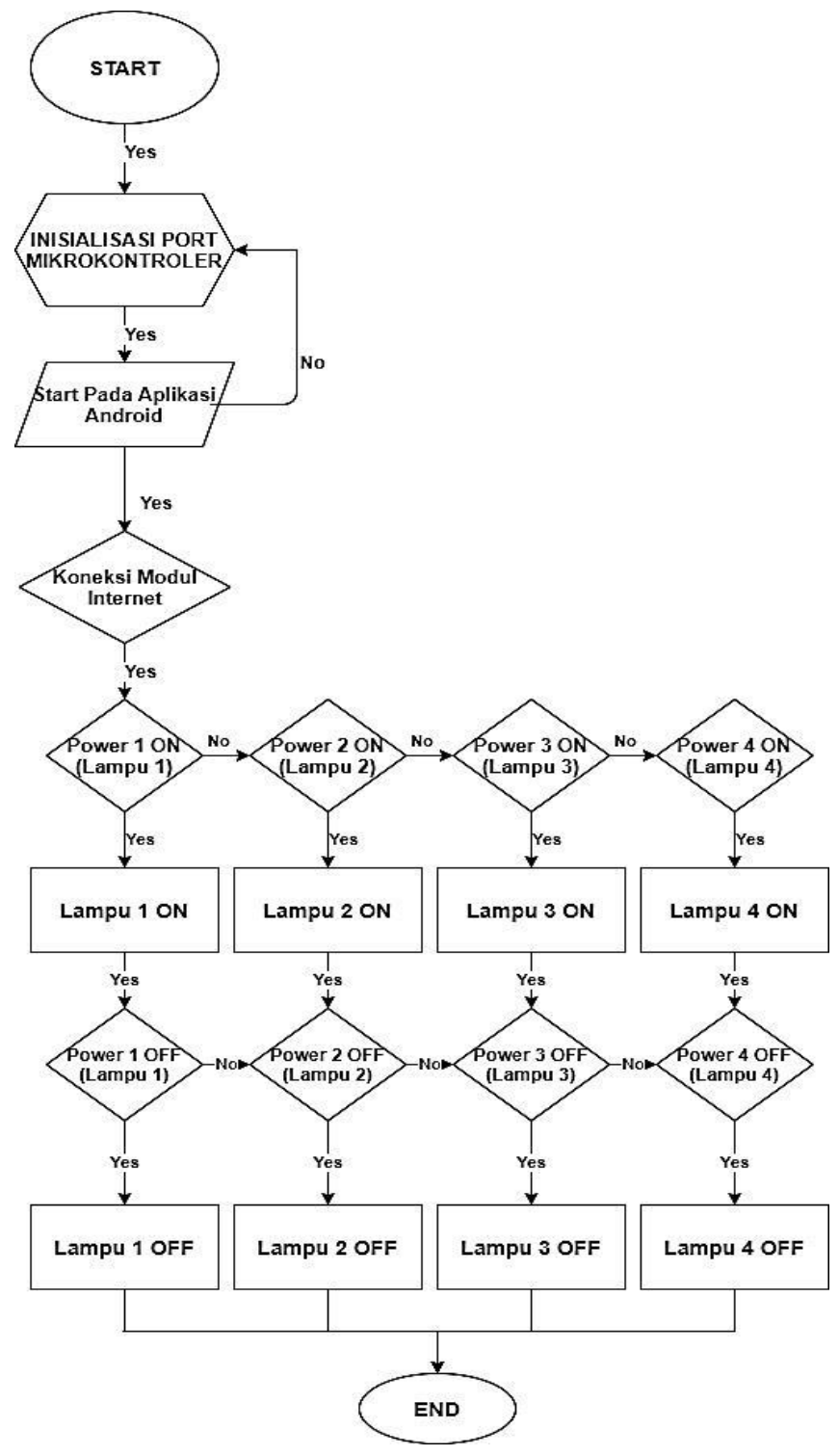

Gambar 7. Flowchart Sistem

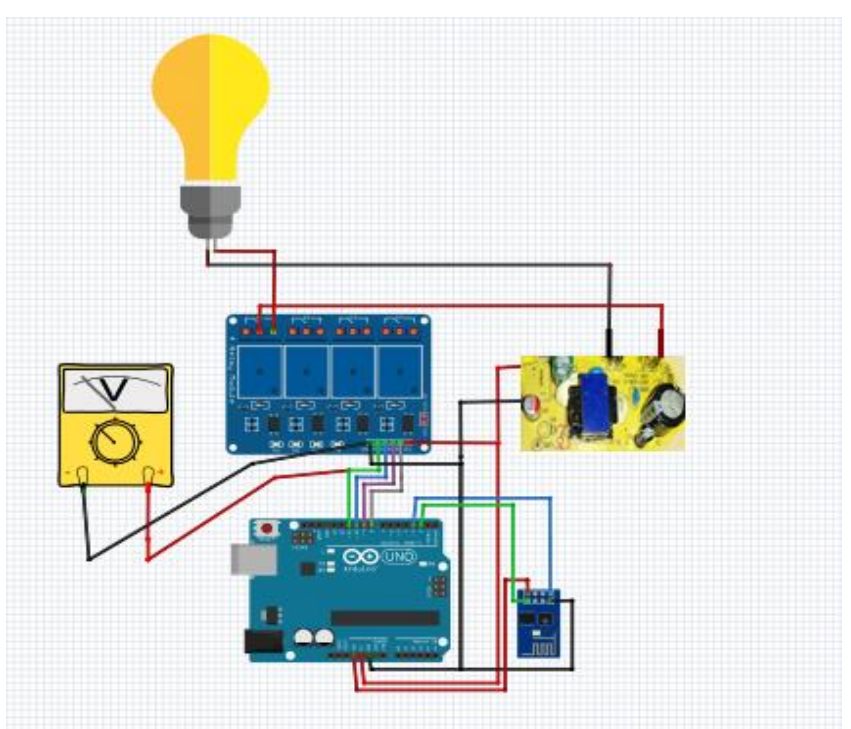

Gambar 8. Rangkaian Alat Keseluruhan

\section{HASIL DAN PEMBAHASAN}

Terdapat beberapa percobaan dan pengujian alat untuk sistem yang telah dibuat. Pengujian alat dilakukan untuk melihat sejauh mana kinerja dari alat yang telah dibuat secara Software maupun hardware. Hasil uji alat diperlihatkan pada tabel 1.

Tabel 1. Pengujian Alat Keseluruhan

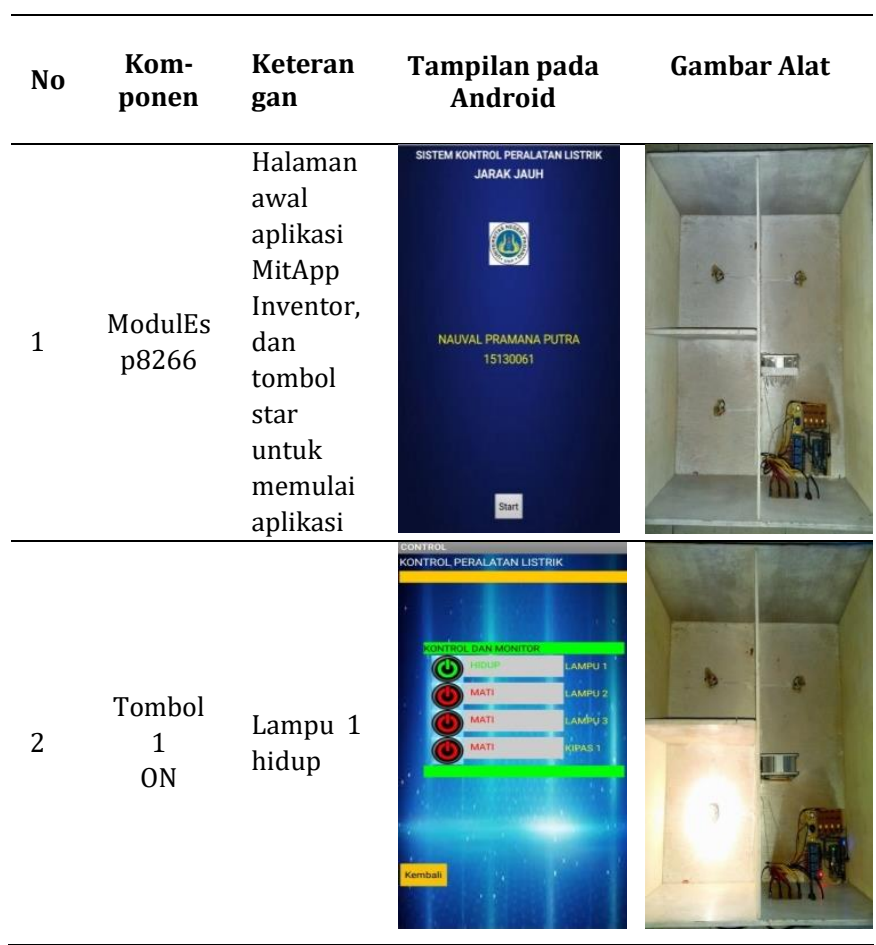




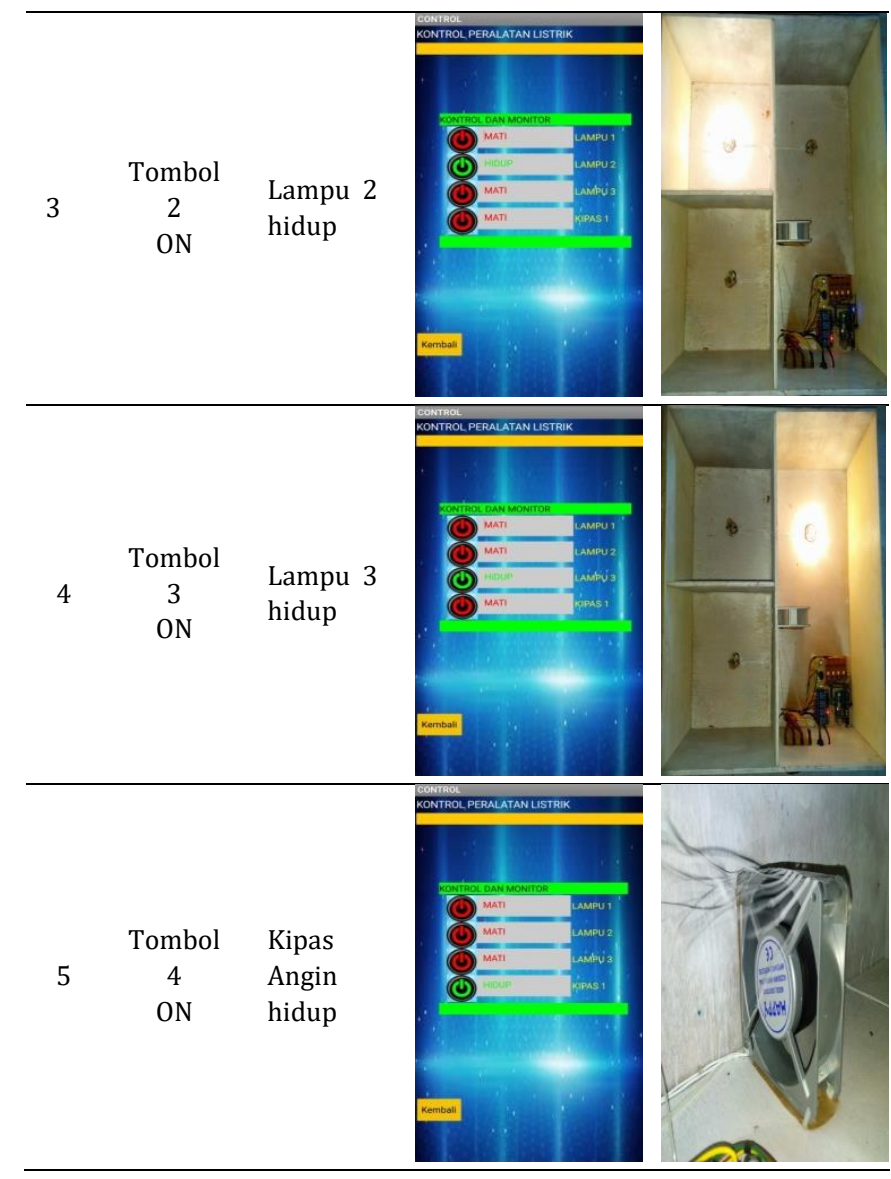

Berdasarkan pengujian pada tabel 1 dapat disimpulkan bahwa sistem bekerja sesuai dengan yang diharapkan. Saat modul dan android terhubung dengan jaringan internet. Pada saat tombol ditekan ON maka lampu akan hidup, kemudian saat tombol ditekan OFF lampu mati sesuai dengan tombol yang ditekan. Jangkauan kendali peralatan listrik ini tidak terbatas selama jaringan internet tersedia dan kecepatan internet dalam keadaan normal. Dan untuk mengontrol peralatan listrik paket data pada android harus aktif untuk mengirim data pada server dan diterima oleh modul agar alat berjalan sesuai dengan perintah pada android.

\section{PENUTUP}

Berdasarkan pengujian yang telah dilakukan terhadap alat aplikasi pengontrolan lampu dan kipas AC bebasis arduino, maka dapat diperoleh cara pembuatan hardware dan software pengontrolan lampu jarak jauh berbasis arduino dapat diaplikasikan untuk ON/Off sebanyak 3 buah lampu $220 \mathrm{~V}$ dan kipas angin $220 \mathrm{~V}$ yang dihubungkan dengan relay 4 channel, serta hasil unjuk kerja dari aplikasi melalui Esp8266 berbasis arduino dapat bekerja sesuai dengan yang direncanakan yaitu lampu dan kipas AC dapat hidup pada saat tambol on ditekan dan mati dengan tombol off ditekan dengan kecepatan internet dalam keadaan stabil.

\section{REFERENSI}

[1] A. M. Alipudin, "Rancang bangun alat monitoring biaya listrik terpakai berbasis internet of things (iot)," J. Online Mhs. Bid. Tek. Elektro, vol. 1, no. 1, 2018.

[2] S. Muliarni and I. Husnaini, "Aplikasi Pengontrolan Lampu dan Motor DC Berbasis Arduino," JTEV (Jurnal Tek. Elektro dan Vokasional), vol. 6, no. 2, pp. 285291, 2020.

[3] D. M. Gumelar, M. Rivai, and T. Tasripan, "Rancang Bangun Wireless Electronic Nose Berbasis Teknologi Internet of Things," J. Tek. ITS, vol. 6, no. 2, pp. A750A752, 2017.

[4] H. G. Kaunang, Y. Ndabuke, and J. Munaiseche, "Perancangan dan Implementasi Sistem Kendali Jarak Jauh Saklar Lampu Rumah Menggunakan Bluetooth Berbasis Arduino," J. Electr., vol. 3, no. 1, pp. 1-7, 2015.

[5] M. Safii and V. Vidy, "Perancangan bangun alat monitoring notifikasi tegangan genset berbasis internet of things dan sms gateway," Sebatik, vol. 23, no. 1, pp. 178-184, 2019.

[6] N. A. A. Kusuma, "Rancang bangun smart home menggunakan wemos d1 r2 arduino compatible berbasis esp8266 esp-12f." Fakultas Sains dan Teknologi Universitas Islam Negeri Syarif Hidayatullah ..., 2018.

[7] A. Kadir, Pemrograman Arduino \& Android Menggunakan App Inventor. Elex Media Komputindo, 2017.

\section{Biodata Penulis}

Nauval Pramana Putra dilahirkan di Padang Pariaman, 29 Juni 1996, menyelesaikan Program Study DIV Teknik Elektro Industri pada jurusan Teknik Elektro Fakultas Teknik Universitas Negeri Padang.

Irma Husnaini, ST, MT, dilahirkan di Bukittinggi 29 September 1972, menyelesaikan S1 di Universitas Negeri Padang dan S2 di Institut Teknologi Bandung Bandung. Staf pengajar tetap di jurusan Teknik Elektro Fakultas Teknik Universitas Negeri Padang sampai sekarang. 